\title{
Tội phạm tình dục tại Đồng Nai qua giám định y pháp trong 3 năm từ 2010 đến 2012
}

\author{
Lưu Sỹ Hùng ${ }^{1, *}$, Trần Văn Hoàng ${ }^{2}$, Nguyễn Tuấn Anh $^{1}$, Trịnh Xuân Hà \\ ${ }^{1}$ Bộ môn Y pháp đại học Y Hà Nội, số 1 Tôn Thất Tùng, Đống Đa, Hà Nội, Việt Nam \\ ${ }^{2}$ Trung tâm Pháp y tỉnh Đồng Nai, số 22 Nguyền Hiền Vuơng, Thanh Bình, Biên Hoà, Đồng Nai, Việt Nam \\ ${ }^{3}$ Trung tâm Pháp Y Hà Nội, 35 Trần Bình, Mai Dịch, Cầu Giấy, Hà Nội, Việt Nam \\ Nhận ngày 21 tháng 3 năm 2017 \\ Chỉnh sửa ngày 18 tháng 4 năm 2017; Chấp nhận đăng ngày 14 tháng 6 năm 2017
}

\begin{abstract}
Tóm tắt: Tội phạm tình dục hiện đang tăng nhanh gây ảnh hưởng sâu sắc đến sức khỏe của nạn nhân. Nghiên cứu được thực hiện tại trung tâm Pháp Y Đồng Nai trong thời gian từ 01/01/2010 đến 30/10/2012, chúng tôi thu thập được 354 nạn nhân. Số nạn nhân ở lứa tuổi dưới 15 là $63,1 \%$; từ 16 - 25 là $33,3 \%$; hiếm gặp trên 36 tuổi. Trong đó $4,8 \%$ số nạn nhân đến khám ngay sau khi bị nạn; trong $12 \mathrm{~h}$ là $18,6 \%$; sau $24 \mathrm{~h}$ là $15,1 \%$ và $13 \%$ nạn nhân đến khám sau 1 tháng. Số nạn nhân bị thương tích ở các vị trí ngoài vùng sinh dục chiếm $4,9 \%$; chủ yếu gặp xây sát da tay, chân. Rách màng trinh chiếm tỷ lệ $66,9 \%$ bao gồm rách cũ và mới; tụ máu màng trinh chiếm $13,8 \%$. Có $33,1 \%$ số nạn nhân không rách màng trinh.
\end{abstract}

Từ khóa: Tội phạm tình dục, giám định Pháp y, vùng sinh dục, màng trinh, rách màng trinh cũ và mới.

\section{1. Đặt vấn đề}

Do tác động nhiều mặt của đời sống xã hội, số vụ tội phạm tình dục hiện đang tăng nhanh, rất đa dạng và mở rộng trên phạm vi toàn cầu cũng như ở Việt Nam. Bạo lực tình dục thường gây ra những ảnh hưởng sâu sắc đến sức khỏe của nạn nhân do bị thương tích, vấn đề tình dục và sinh sản cũng như suy sụp về tinh thần [1]. Năm 2002, Tổ chức Y tế thế giới (W.H.O) đưa ra "Báo cáo thế giới về bạo lực và sức khỏe", là báo cáo đầu tiên của loại hình này về vấn đề bạo lực tình dục, được xem là vấn đề nghiêm trọng với sức khỏe của cộng đồng. Từ những nhận thức về tầm quan trọng của vấn đề nêu

\footnotetext{
* Tác giả liên hệ. ĐT.: 84-945963399.

Email: drlshung@gmail.com

https://doi.org/10.25073/2588-1132/vnumps.4054
}

trên, đề tài "Tội phạm tình dục tại Đồng Nai qua giám định Y Pháp trong 3 năm 2010 2012" được tiến hành nhằm tìm hiểu mối liên quan về tuổi, thời gian và hình thái tổn thương bộ phận sinh dục ở những nạn nhân đã được giám định tại trung tâm Pháp Y tỉnh Đồng Nai, qua đó đưa ra những nhận xét với hy vọng góp phần làm cho công tác giám định $\mathrm{Y}$ Pháp từng bước được hoàn chỉnh hơn.

\section{2. Đối tượng và phương pháp nghiên cứu}

\section{1. Đối tuợng nghiên cứu}

Là những nạn nhân được Trung tâm Pháp Y tỉnh Đồng Nai giám định trong thời gian từ 01/1/2010 đến 30/10/2012, chúng tôi thu thập được 354 trường hợp, toàn bộ số nạn nhân đều là nữ giới. 


\subsection{Phương pháp nghiên cúu}

Nghiên cứu mô tả bao gồm hồi cứu và tiến cứu

- Hồi cứu từ 01/1/2010 đến 30/10/2011

- Tiến cứu từ 1/11/2011 đến 30/10/2012

\subsection{Xử lý số liệu}

Các đối tượng nghiên cứu được khai thác đầy đủ thông tin về:

- Tuổi: Sắp xếp theo bảng phân loại nhóm tuổi của WHO

- Nơi xảy ra tai nạn : sắp xếp theo thành phố, thị xã, nông thôn ...

- Khoảng thời gian từ khi bị nạn đến khi được đi giám định: Lập bảng theo khoảng thời gian kể từ khi bị nạn đến khi được giám định

- Lập bảng thống kê và phân loại tổn thương trên thân thể nạn nhân cũng như tại vùng sinh dục

- Phân loại tổn thương: Tổn thương tại vùng hậu môn sinh dục bao gồm tổn thương tại vùng mu, môi lớn, môi nhỏ, quanh lỗ đái, đáy chậu và tổn thương bên trong tại tiền đình, màng trinh, âm đạo và cổ tử cung, hậu môn - trực tràng $[1,2,4]$.

- Số liệu thu thập được xử lý trên phần mềm Excel 2007.

\section{Kết quả nghiên cứu}

\subsection{Tuổi nạn nhân}

Bảng 1. Thống kê tuổi

\begin{tabular}{lcc}
\hline Tuổi & Số lượng & Tỷ lệ (\%) \\
\hline $1-15$ & 223 & 63,1 \\
$16-25$ & 118 & 33,3 \\
$26-35$ & 08 & 2,1 \\
$36-60$ & 03 & 0,9 \\
$>60$ & 02 & 0,6 \\
Tổng & 354 & $100 \%$ \\
\hline
\end{tabular}

Nhận xét: Số nạn nhân chủ yếu ở lứa tuổi dưới 15 với tỷ lệ $63,1 \%$, số nạn nhân từ $16-25$ là $33,3 \%$. hiếm gặp trên 36 tuổi.

\subsection{Nơ xảy ra}

Bảng 2. Nơi xảy ra

\begin{tabular}{lcc}
\hline Nơi xảy ra & Số lượng & Tỷ lệ \% \\
\hline Thành phố & 105 & 29,7 \\
Huyện - thị xã & 80 & 22,6 \\
Vùng xa xôi & 152 & 42,9 \\
Không rõ & 17 & 4,8 \\
Tổng & 354 & $100 \%$ \\
\hline
\end{tabular}

Nhận xét: Số vụ việc xảy ra ở vùng xa xôi hẻo lánh chiếm $42,9 \%$

\subsection{Thời gian đến khám}

Bảng 3. Thời gian đến khám

\begin{tabular}{lcc}
\hline Loại & Số lượng & Tổng (\%) \\
\hline Trong giờ đầu & 17 & 4,8 \\
Trước 12h & 66 & 18,6 \\
Sau 24h & 53 & 15,1 \\
Sau 48h & 23 & 6,5 \\
Sau 72h & 45 & 12,7 \\
Sau 5 ngày & 21 & 5,9 \\
Sau 1 tuần & 63 & 17,8 \\
Sau 1 tháng & 46 & 13,0 \\
Không xác định & 20 & 5,6 \\
Tổng & 354 & $100 \%$ \\
\hline
\end{tabular}

Nhận xét: Có 4,8 \% số nạn nhân đến khám ngay sau khi bị nạn, trong $12 \mathrm{~h}$ là $18,6 \%$, sau 24 h là $15,1 \%$. Có $13 \%$ nạn nhân đến khám sau 1 tháng.

\subsection{Tổn thuơng ở các vùng trên thân thể nạn nhân}

Bảng 4. Tổn thương ở các vùng trên thân thể nạn nhân

\begin{tabular}{lcc}
\hline Nơi tổn thương & Số lượng & Tổng (\%) \\
\hline Đầu mặt & 02 & \\
Cổ & 01 & 4,9 \\
Ngực/Bụng & 02 & \\
Lưng & 02 & \\
Tay chân & 11 & \\
$\begin{array}{l}\text { Không có } \\
\text { thương tích }\end{array}$ & 336 & 95,1 \\
Tổng & 354 & $100 \%$ \\
\hline
\end{tabular}

Nhận xét: Số nạn nhân bị thương tích ở các vị trí ngoài vùng sinh dục chiếm $4,9 \%$, chủ yếu gặp xây sát da tay, chân. 


\subsection{Phân loại tổn thuoong tại bộ phận sinh dục}

Bảng 5. Phân loại tổn thương tại bộ phận sinh dục

\begin{tabular}{lcccccccc}
\hline $\begin{array}{l}\text { Phân loại tổn } \\
\text { thương }\end{array}$ & $\begin{array}{c}\text { Xây } \\
\text { sát }\end{array}$ & $\begin{array}{c}\text { Tỷ lệ } \\
(\%)\end{array}$ & $\begin{array}{c}\text { Bầm tụ } \\
\text { máu }\end{array}$ & $\begin{array}{c}\text { Tỷ lệ } \\
(\%)\end{array}$ & Rách & $\begin{array}{c}\text { Tỷ lệ } \\
(\%)\end{array}$ & $\begin{array}{c}\text { Tổn thương } \\
\text { khác }\end{array}$ & $\begin{array}{c}\text { Tỷ lệ } \\
(\%)\end{array}$ \\
\hline Vùng sinh dục & 03 & 0,9 & 03 & 0,9 & 00 & 0,0 & 00 & 0,0 \\
Môi lớn & 03 & 0,9 & 03 & 0,9 & 00 & 0,0 & 00 & 0,0 \\
Môi nhỏ & 02 & 0,6 & 30 & 8,5 & 00 & 0,0 & 00 & 0,0 \\
Màng trinh & 00 & 0,0 & 49 & 13,8 & 237 & 66,9 & 00 & 0,0 \\
Âm đạo & 02 & 0,6 & 03 & 0,9 & 02 & 0,6 & 07 & 2,0 \\
Tầng sinh môn & 07 & 2,0 & 00 & 0,0 & 02 & 0,6 & 00 & 0,0 \\
Không tổn & 337 & 95,0 & 266 & 75,0 & 113 & 31,9 & 347 & 98,0 \\
thương & 354 & $100 \%$ & 354 & $100 \%$ & 354 & $100 \%$ & 354 & $100 \%$ \\
Tổng & & & & & & & &
\end{tabular}

Nhận xét: Rách màng trinh chiếm tỷ lệ $66,9 \%$ bao gồm rách cũ và mới, tụ máu màng trinh chiếm $13,8 \%$.

\subsection{Phân loại hình thái màng trinh}

Bảng 6. Phân loại hình thái màng trinh

\begin{tabular}{lll}
\hline Loại & Số ca & Tỷ lệ\% \\
\hline Hình hoa khế & 42 & 11,9 \\
Hình khe & 40 & 11,3 \\
Hình Tròn & 61 & 17,2 \\
Hình bán nguyệt & 84 & 23,7 \\
Hình chóp & 110 & 31,1 \\
Không rõ & 17 & 4,8 \\
Tổng & 354 & $100 \%$ \\
\hline
\end{tabular}

Nhận xét: Màng trinh hình chóp chiếm $31,1 \%$, tiếp đến là màng trinh hình bán nguyệt 23,7\%. Màng trinh hình tròn, hoa khế, bán nguyệt có tỷ lệ ngang nhau.

\subsection{Phân loại tổn thương màng trinh}

Bảng 7. Phân loại tổn thương màng trinh

\begin{tabular}{lcc}
\hline $\begin{array}{l}\text { Phân loại tổn } \\
\text { thương màng trinh }\end{array}$ & Số lượng & Tổng (\%) \\
\hline Không rách & 117 & 33,1 \\
Rách mới & 49 & 13,8 \\
Rách cũ & 188 & 53,1 \\
Tổng & 354 & $100 \%$ \\
\hline
\end{tabular}

Nhận xét: Tỷ lệ rách cũ màng trinh chiếm đa số với $53,1 \%$, rách mới là $13,8 \%$. Có 33,1\% số nạn nhân không rách màng trinh.

\section{Bàn luận}

Tuổi nạn nhân: Số liệu ở bảng 1 cho thấy trẻ em dưới 15 tuổi chiếm tỷ lệ cao nhất với $63,1 \%$, tiếp đến là nạn nhân trong nhóm tuổi $16-25$ với tỷ lệ 33,3\%. Các nhà nghiên cứu xã hội học cho rằng ở lứa tuổi này do ý thức và sự hiểu biết chưa đầy đủ nên nạn nhân dễ bị dụ dỗ hoặc vì sự đua đòi theo bạn bè, hoặc nạn nhân còn nhỏ không có khả năng chống đỡ trước hung thủ. Trong nghiên cứu chúng tôi ghi nhận nạn nhân nhỏ tuổi nhất là cháu gái chưa đầy 1 tuổi (SHS: 1139/GĐPY/2011). Hiếp dâm trẻ em hiện đang là vấn nạn ở nhiều quốc gia trên thế giới và Việt $\operatorname{Nam}[1,3,6]$.

Nơi xảy ra: Bảng 2 ghi nhận số nạn nhân ở vùng xa xôi hẻo lánh chiếm $42,9 \%$, tiếp đến là nhóm nạn nhân ở thành phố với tỷ lệ $29,7 \%$ và thị xã - huyện là $22,6 \%$. Số liệu trong nghiên cứu của chúng tôi có khác so với số liệu trong các nghiên cứu trước đây về tình hình tội phạm tình dục, số liệu trong các công trình nghiên cứu trước đều ghi nhận số vụ việc xảy ra chủ yếu tại các địa bàn thành phố, thị xã hoặc khu du lịch. Có thể do sự phát triển kinh tế đã xóa đi 
sự khác biệt về khoảng cách vùng miền và đặc biệt là sự phát triển về internet đã góp phần tạo nên sự khác biệt so với trước đây [1].

Thời gian đến khám: Có 17 nạn nhân đến giám định trong trong vòng $1 \mathrm{~h}$ kể từ sau khi bị nạn $(4,8 \%)$, chậm nhất là sau 1 tháng có 46 nạn nhân $(5,6 \%)$. Trường hợp nạn nhân đến giám định sớm hay muộn phụ thuộc vào rất nhiều yếu tố tâm lý như xấu hổ, sợ hãi, tủi thân dẫn đến khai báo muộn, bảng .3 cho thấy số nạn nhân đến khám sau 1 tuần là $17,8 \%$. Chính điều này đã làm ảnh hưởng đến chất lượng của kết luận giám định khi mà các dấu vết sinh học không còn, các vết thương đã tự khỏi, nhiều trường hợp do nạn nhân không khai báo kịp thời đã dẫn đến những hậu quả đáng tiếc như bị viêm nhiễm đường sinh dục (bảng 3.5) hoặc nhiều nạn nhân khi đến giám định đã có thai (SHS: 0271/GĐPY/2010, 0578/ GĐPY/2010, 1234/GĐPY/2010...).

Tổn thương trên thân thể nạn nhân (ngoài vùng sinh dục): Trong tổng số 354 nạn nhân, số nạn nhân bị thương tích ở các vùng trên thân thể chủ yếu là những tổn thương bên ngoài như xây sát da, bầm tụ rách da... không gặp trường hợp nào có chấn thương nội tạng, ngoại trừ 1 trường hợp nạn nhân sinh năm 1986 khi đến giám định có bị gãy đầu dưới xương quay đã được nẹp bột cố định (SHS: 0988/GĐPY/2010), trong hồ sơ giám định không thấy xác định tổn thương này là hậu quả trực tiếp của hành vi xâm hại tình dục hay nạn nhân bị thương từ trước khi sự việc xảy ra. Kết quả nghiên cứu của chúng tôi phù hợp với số liệu báo cáo của nhiều tác giả trong và ngoài nước khi nghiên cứu về phân loại và mức độ thương tích trên thân thể nạn nhân bị cưỡng bức tình dục $[1,2]$.

Tổn thuơng tại co quan sinh dục: Theo phân loại của Sommers (2006) và Slaughter \& Brown (1992) chấn thương bộ phận sinh dục là bất kỳ tổn thương nào xảy ra tại vùng hậu môn sinh dục bao gồm tổn thương bên ngoài như vùng mu, môi lớn, môi nhỏ, quanh lỗ đái, đáy chậu và tổn thương bên trong như hố tiền đình, màng trinh, âm đạo và cổ tử cung, hậu môn trực tràng [6]. Trong nghiên cứu, chúng tôi ghi nhận tổn thương nặng nhất mà nạn nhân phải gánh chịu là rách tầng sinh môn, trong đó 1 trường hợp nạn nhân là cháu bé phải gửi đi bệnh viện Nhi Đồng TP HCM để điều trị (SHS: 0649/GĐPY 2010). Tổn thương hay gặp nhất là rách màng trinh trong đó rách mới là 49 và rách cũ là 188 (bảng 7), tiếp đến là bầm tụ máu môi nhỏ với tỷ lệ $8,5 \%$.

Tổn thương xây sát da bầm tụ máu ở môi lớn, âm đạo, tầng sinh môn chỉ xuất hiện với tỷ lệ rất nhỏ, có thể do nạn nhân đến khám muộn hoặc do tổn thương nhẹ nên không để lại dấu vết sau một vài ngày. Số liệu trong nghiên cứu của chúng tôi phù hợp với kết quả nghiên cứu của nhiều tác giả nước ngoài về mức độ và tỷ lệ tổn thương bộ phận sinh dục ở những nạn nhân bị tấn công tình dục. Theo các tác giả nước ngoài, số liệu khác nhau tùy theo cách khám với phạm vi từ $5 \%$ bằng phương pháp quan sát trực tiếp bằng mắt thường (Massey et $\mathrm{al}, 1971$ ) đến $87 \%$ với kỹ thuật soi cổ tử cung (Slaughter \& Brown, 1992) [5].

Trong một nghiên cứu trên 480 nạn nhân bị cưỡng/ hiếp dâm, Massey và cộng sự (1971) ghi nhận chỉ có $5,2 \%$ số nạn nhân bị tổn thương bộ phận sinh dục khi khám bằng mắt thường. Cũng theo phương pháp này Hayman và cộng sự (1972) khi thăm khám cho 1233 phụ nữ và trẻ em bị cưỡng hiếp dâm ghi nhận có 20 nạn nhân bị rách âm đạo và túi cùng hậu môn âm đạo và 199 nạn nhân bị thương nhẹ ở bộ phận sinh dục [5]. Trên toàn bộ số nạn nhân nghiên cứu chúng tôi không gặp trường hợp nào có tổn thương ở hậu môn - trực tràng, có thể đó là dấu hiệu khác biệt so với tội phạm tình dục ở nước ngoài cho đến thời điểm hiện tại.

Phân loại màng trinh: Có nhiều cách phân loại màng trinh như dựa vào đặc điểm cấu trúc giải phẫu (màng trinh bịt, màng trinh có nhiều lỗ nhỏ, bề mặt có lông, không có màng trinh hoặc màng trinh chun có độ đàn hồi tốt, không bị tổn thương khi quan hệ tình dục). Trong giám định Pháp Y, nhiều tác giả dựa trên hình thái lỗ màng trinh để đặt tên cho loại hình màng trinh như hình tròn hay hình vành khăn, hình đài hoa hay hình hoa khế, hình bán nguyệt, hình sàng $[2,4]$. Số liệu ở bảng 6 cho thấy một số loại hình màng trinh hay 
gặp như màng trinh hình chóp $(31,1 \%)$, hình tròn $(17,2 \%)$, hình đài hoa $(11,9 \%) \ldots$

Theo chúng tôi, cách phân loại và đặt tên cho màng trinh là tùy thuộc ở mỗi người, nhưng quan trọng hơn là nhận biết đúng loại hình màng trinh để có thể phân biệt được tổn thương rách màng trinh thật hay giả. Nhiều tác giả trong và ngoài nước đã ghi nhận trên bề mặt màng trinh hình đài hoa có nhiều nếp gấp nên rất dễ bị nhầm với vết rách màng trinh nếu giám định viên không có kinh nghiệm [1,4]. Trong nghiên cứu chúng tôi gặp một trường hợp màng trinh hình chóp có lưỡi, có nếp gấp rất giống với vết rách màng trinh nhưng giám định viên đã phát hiện và kết luận không có rách màng trinh. Điều cần thiết là phải cung cấp thông tin để các bác sỹ khoa Sản khi khám màng trinh phải hết sức chú ý và đặc biệt là không nên vội kết luận có rách màng trinh, tránh gây hiểu lầm cho nạn nhân và người nhà cũng như cơ quan tiến hành tố tụng.

Tổn thương rách màng trinh: Số liệu ở bảng 7 cho thấy tỷ lệ rách màng trinh là $66,9 \%$ trong đó rách mới là 49 và rách cũ là 188 $(53,1 \%)$. Theo chúng tôi, trong số nạn nhân được kết luận có rách màng trinh cũ cần phải hết sức thận trọng vì khi nạn nhân đến muộn, vết rách màng trinh đã liền sẹo nên có thể làm cho giám định viên dễ nhầm lẫn trong kết luận giám định.

Do phạm vi của bài báo và nhiều lý do khách quan nên chúng tôi chưa thể tiến hành đánh giá mối liên quan giữa vị trí tổn thương rách màng trinh và loại hình màng trinh

\section{Kết luận}

Qua nghiên cứu hồ sơ của 354 nạn nhân được giám định pháp $\mathrm{y}$ trong thời gian từ
01/1/2010 đến 30/10/2012 chúng tôi đi đến kết luận:

- Nạn nhân của tội phạm tình dục chủ yếu là dưới 15 tuổi $(63,1 \%)$ và trong độ tuổi $16-25$ $(33,3 \%)$.

- Nơi xảy ra tập trung chủ yếu ở vùng xa xôi hẻo lánh và thành phố.

- Trên $50 \%$ số vụ việc đến khám muộn (sau $72 \mathrm{~h}$ đên 1 tháng)

- Tổn thương bộ phận sinh dục chủ yếu là rách màng trinh cũ và mới, mức độ nhẹ nhưng cũng có trường hợp phải có chăm sóc y tế.

\section{Tài liệu tham khảo}

[1] Bài giảng Y Pháp học (2007), NXB Y học - Hà Nội.Vũ Ngọc Thụ (1992), Y học Tư pháp - NXB Y học - Hà Nội.

[2] Bộ Luật Tố tụng Hình sự của nước Cộng hoà xã hội chủ nghĩa Việt Nam. Nhà xuất bản Chính trị Quốc Gia, Điều 112 trang 74, Điều 113 trang 76, Điều 114 trang 77, Điều 116 trang 78.

[3] Knight B. 1988."A Model Medico-Legal System." For. Sci. Int. 39:1-4.

[4] Lucy Bowyer, Maureen E. Dalton (1997). Female victims of rape and their genital injuries. British Journal of Obtestrics and Gynaecology, Vol.104. 617-620.

[5] Marilyn Sawyer Sommers (2007). TRAUMA, VIOLENCE, \& ABUSE, Vol. 8 (3), 270-280

[6] Massey, J. B., Garcia, C. R., \& Emich, J. P., Jr. (1971). Management of sexually assaulted females. Obstetrics and Gynecology, 38(1), 29-36.

[7] Sommers, M. S., Zink, T., Baker, R. B., Fargo, J. D., Porter, J., Weybright, D., et al. (2006). Effects of age and ethnicity on physical injury from rape. Journal of Obstetric, Gynecologic and Neonatal Nursing, 35(2), 199-207. 


\title{
Sex Crime in Dong Nai Province through Forensic Exam in 3 Years from 2010 to 2012
}

\author{
Luu Sy Hung ${ }^{1}$, Tran Van Hoang ${ }^{2}$, Nguyen Tuan $\mathrm{Anh}^{1}$, Trinh Xuan $\mathrm{Ha}^{3}$ \\ ${ }^{l}$ Dept of Forensic Medicine, Ha Noi Medical University, \\ No 01, Ton That Tung Str, Dong Da Dist, Hanoi, Vietnam \\ ${ }^{2}$ Dong Nai Forensic centre, No 22, Nguyen Hien Vuong Str, Thanh Binh Ward, \\ Bien Hoa City, Dong Nai Province, Vietnam \\ ${ }^{3}$ Hanoi Forensic centre, No 35, Tran Binh str, Mai Dich Ward, Cau Giay Dist, Hanoi, Vietnam
}

\begin{abstract}
Sexual crime is increasing profound impact on the health of the victim. This study was conducted at the Forensic Centre of Dong Nai province in the period from 01/1/2010 to 10/30/2012, with total of 354 victims. Number of victims aged under 15 is $63.1 \%$, from $16-25$ is $33.3 \%$. Rare on $36.4 .8 \%$ of the victim to the doctor immediately after the event, $18.6 \%$ of the victim after $12 \mathrm{pm}$. after 24 hours was $15.1 \%$ and $13 \%$ of victims to examination after 1 month. Number of victims injured at outside of the genital area accounted for $4.9 \%$, mainly with scratch in extrimities. Injuries of the hymen with $66.9 \%$ including the old and new tears, hematoma at the hymen was $13.8 \%$ and $33.1 \%$ of the victims have no sight of injuries on the hymen.
\end{abstract}

Keywords: Sexual crime, forerensic exam, hymen, hymen injuries, regional genital. 